
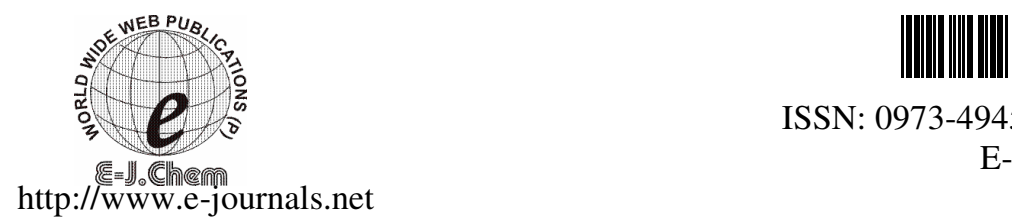

ISSN: 0973-4945; CODEN ECJHAO

E-Journal of Chemistry 2010, 7(S1), S7-S14

\title{
Identification of New Aromatic Compounds in the New Zealand Manuka Honey by Gas Chromatography-Mass Spectrometry
}

\author{
SAWSAN DAHER ${ }^{*}$ and FAZIL O. GÜLAÇAR \\ Laboratory of Mass Spectrometry \\ Physical Chemistry, University of Geneva, Sciences I \\ Boulevard d'Ivoy 16, CH-1211 Geneva 4, Switzerland \\ sawsan_daher@hotmail.com
}

Received 16 January 2010; Accepted 10 March 2010

\begin{abstract}
Analysis of aromatic compounds in the New Zealand manuka honey was carried out by solid phase microextraction followed by gas chromatography-mass spectrometry. A total of 38 compounds were detected. Seven of them such as; 1,4-bis( $x$-methoxyphenyl)-but-2-en-1-one, 1,5-bis(xmethoxyphenyl)-pent-3-en-1-one, 1,4-bis( $x$-methoxyphenyl)-1-pentanone, 1,6$\operatorname{bis}(x$-methoxyphenyl)-3-heptene, 1,6-bis( $x$-methoxyphenyl)-hex-2(3 or 4)-en1-one and 2(3, 4 or 5)-hydroxy-1,6-bis(x-methoxyphenyl)-1-hexanone, had never before been identified as natural products. Their structures were deduced from the mass spectral data. Seven other compounds; 2,3-dimethoxynaphthalene, 4-( $x$-methoxyphenyl)-1-phenyl-1-butanone, desoxyanisoin, 2,6-dimethoxybenzoic acid benzyl ester, 4,4'-dimethoxystilbene, 3,3,4,5,5,8-hexamethyl-2,3,5,6tetrahydro-s-indacene-1,7-dione and 1,5-bis(4-methoxyphenyl)-pentane-1,5dione, were found in honey for the first time. Methyl syringate, orthomethoxyacetophenone and 3-phenyllactic acid were the most abundant components.
\end{abstract}

Keywords: Manuka honey, Aromatic compounds, Solid phase microextraction, GC-MS.

\section{Introduction}

Manuka honey, produced from the New Zealand's manuka tree (Leptospermum scoparium), has been shown to have a high antibacterial activity ${ }^{1-5}$. It is used against the helicobacter pylori $^{3,6}$ and as a dressing for the treatment of chronic wounds ${ }^{5,7}$ or ulcers ${ }^{8}$. The antibacterial activity of the honey is generally attributed to the presence of hydrogen peroxide. However, after destruction of this, a residual non-peroxide antibacterial activity was also observed 
in some honeys, for example certain active manuka honeys derived from specific localities ${ }^{2,9}$. Several studies have attempted to give evidence of the principal factor responsible for such activity $^{1,10,11}$, but none have been successful thus far $^{12}$. Inoue et al. ${ }^{13}$ demonstrated that manuka honey had a radical scavenging activity for superoxide anion radicals due to the presence of methyl syringate.

In a recent work, we demonstrated the usefulness of solid-phase microextraction (SPME) followed by gas chromatography-mass spectrometry (GC-MS) for the analysis of phenolic and other aromatic constituents in honeys ${ }^{14}$. In the present paper we report the results from application of this method to the manuka honey that led to the identification of seven new aromatic compounds. The determination of their structures was made by interpretation of their mass spectral fragmentation patterns. In addition, seven compounds were found in the honey for the first time.

Several aromatic compounds identified had one or more methoxy groups. It is known that methoxylation increases the degree of a product's lipophilicity, improves metabolic stability and consequently the biological activity of that product ${ }^{15,16}$.

\section{Experimental}

Two samples of manuka honey from New Zealand were purchased from a local market. The beekeeper associations supplied honey samples to this market asserting their floral and geographical origins.

Standards were purchased from Sigma-Aldrich Chemie, Buchs, Switzerland, benzoic acid, 4-methoxy-benzoic acid, 2-methoxybenzoic acid, 4-hydroxy-3-methoxybenzoic acid methyl ester, methyl syringate, chrysin and $n$-paraffin mix (C10-C36). The polyacrylate (PA) $85 \mu \mathrm{m}$ SPME fiber was also obtained from Sigma-Aldrich Chemie.

\section{Solid phase microextraction (SPME)}

SPME extraction was carried out as already described ${ }^{14}$. Briefly, $1 \mathrm{~g}$ of honey was placed into a $10 \mathrm{~mL}$ vial. The sample was diluted with $4 \mathrm{~mL}$ of distilled water and then $1 \mathrm{~g}$ of sodium chloride and $0.2 \mathrm{~mL}$ of acetic acid were added. The melange was shaken at room temperature until homogenized. The solution was extracted by immersing the PA fiber into the solution for $30 \mathrm{~min}$ at room temperature. The fiber was then removed from the vial and immediately inserted into the GC-MS injector for thermal desorption of the analytes. The PA fiber was initially conditioned for $2 \mathrm{~h}$ at $300{ }^{\circ} \mathrm{C}$ in a $\mathrm{GC}$ injector under a helium flow.

\section{$G C-M S$ analysis}

Analyses were performed on a Hewlett Packard 5890 gas chromatograph coupled to a VG Masslab Trio-2 mass spectrometer. GC separations were carried out using a J\&W DB-5HT column (30 $\mathrm{m} \times 0.32 \mathrm{~mm} \times 0.1 \mu \mathrm{m}$ of film thickness). A split/splitless injector was used in the splitless mode $(2 \mathrm{~min})$ at a temperature of $300{ }^{\circ} \mathrm{C}$. The oven temperature was programmed as follows: $40{ }^{\circ} \mathrm{C}$ for $1 \mathrm{~min}$, increased to $300{ }^{\circ} \mathrm{C}$ at $3{ }^{\circ} \mathrm{C} / \mathrm{min}$, and held at $300{ }^{\circ} \mathrm{C}$ for $5 \mathrm{~min}$. Helium was the carrier gas at a constant flow of $1 \mathrm{~mL} / \mathrm{min}$. The mass spectrometer was used in the electron impact mode at $70 \mathrm{eV}$ and with a $1.2 \mathrm{~s}$ cycle time in the mass range $m / z 45-600$.

Compounds were identified by comparison of their mass spectra with those in the NIST mass spectral library and identities were confirmed by co-injections of standards when available. Distributions of the studied compounds were calculated from the peak areas in the total ion chromatograms. Kovats indices were determined from the retention times of an $n$-alkane mixture (C10-C36) analyzed under identical conditions. 


\section{Results and Discussion}

The SPME extracts from the two samples (A and $\mathbf{B}$ ) of manuka honey investigated in this work gave GC-MS chromatograms globally similar. Figure 1 shows the chromatogram of the sample A as example. This profile is very distinct from those of the European honeys analysed previously in the same conditions ${ }^{14}$. A total of 38 compounds were detected and most of them were identified (Table 1).

Table 1. Distribution (\% of total) of aromatic compounds extracted from two samples of manuka honey using SPME/GC-MS

\begin{tabular}{|c|c|c|c|c|c|}
\hline \multirow{2}{*}{ Compounds } & \multirow{2}{*}{ No } & \multirow{2}{*}{ MW } & \multirow{2}{*}{ KI } & \multicolumn{2}{|c|}{ Distribution, $\%$} \\
\hline & & & & Manuka A & Manuka B \\
\hline 4-Methylacetophenone & 1 & 134 & 1111 & 0.1 & 0.1 \\
\hline 4-Hydroxyacetophenone & 2 & 136 & 1132 & 0.2 & 0.1 \\
\hline Benzoic Acid & 3 & 122 & 1197 & 0.5 & 0.9 \\
\hline 4-Methoxybenzaldehyde & 4 & 136 & 1233 & 0.3 & 0.6 \\
\hline Ortho-Methoxyacetophenone & 5 & 150 & 1277 & 15.0 & 7.0 \\
\hline 1-Methoxy-4-propyl-benzene & 6 & 150 & 1281 & 1.2 & 5.3 \\
\hline Salicylic Acid & 7 & 138 & 1323 & 1.6 & 1.3 \\
\hline 1-(2-Hydroxy-6-methoxyphenyl)-ethanone & 8 & 166 & 1374 & 0.1 & 0.1 \\
\hline 4-Methoxybenzoic acid & 9 & 152 & 1444 & 0.5 & 1.2 \\
\hline 2-Methoxybenzoic acid & 10 & 152 & 1478 & 1.3 & 0.5 \\
\hline 4-Hydroxy-3-methoxybenzoic acid methyl ester & 11 & 182 & 1500 & 0.1 & 0.2 \\
\hline (4-Methoxyphenyl)-acetic acid & 12 & 166 & 1507 & 0.5 & 1.4 \\
\hline 3-Phenyllactic acid & 13 & 166 & 1548 & 10.2 & 6.5 \\
\hline 2,3-Dimethoxynaphthalene & 14 & 188 & 1553 & 0.3 & 0.1 \\
\hline 3,5-Dimethoxybenzoic acid methyl ester & 15 & 196 & 1558 & 6.6 & 0.8 \\
\hline 3,5-Dimethoxybenzoic acid & 16 & 182 & 1644 & 0.9 & 1.7 \\
\hline Methyl syringate & 17 & 212 & 1772 & 32.3 & 53.5 \\
\hline Unknown & 18 & & 1785 & 5.7 & 0.1 \\
\hline Isomer of $\mathbf{1 8}$ & 19 & & 1812 & 3.8 & 5.1 \\
\hline Unknown & 20 & & 1904 & 1.1 & 1.0 \\
\hline 4-(x-Methoxyphenyl)-1-phenyl-1-butanone & 21 & 254 & 1965 & 0.8 & 0.4 \\
\hline Isomer of 21 & 22 & 254 & 2112 & 0.1 & 0.1 \\
\hline Desoxyanisoin & 23 & 256 & 2155 & 1.0 & 0.6 \\
\hline 2,6-Dimethoxybenzoic acid benzyl ester & 24 & 272 & 2164 & 0.8 & 0.1 \\
\hline 4,4'-Dimethoxystilbene & 25 & 240 & 2254 & 0.3 & 0.4 \\
\hline $\begin{array}{l}\text { 3,3,4,5,5,8-Hexamethyl-2,3,5,6-tetrahydro-s- } \\
\text { indacene-1,7-dione }\end{array}$ & 26 & 270 & 2303 & 0.5 & 0.1 \\
\hline Pinostrobin chalcone & 27 & 270 & 2348 & 0.1 & 0.3 \\
\hline 1,4-Bis(x-methoxyphenyl)-but-2-en-1-one & 28 & 282 & 2439 & 0.2 & 0.1 \\
\hline Pinocembrin & 29 & 256 & 2450 & 0.3 & 2.4 \\
\hline Tectochrysin & 30 & 268 & 2528 & 0.0 & 0.4 \\
\hline 1,5-Bis(4-methoxyphenyl)-pentane-1,5-dione & 31 & 312 & 2631 & 3.0 & 0.9 \\
\hline Chrysin & 32 & 254 & 2641 & 0.0 & $<0.1$ \\
\hline 1,5-Bis( $x$-methoxyphenyl)-pent-3-en-1-one & 33 & 296 & 2652 & 0.5 & 0.0 \\
\hline 1,4-Bis $(x$-methoxyphenyl)-1-pentanone & 34 & 298 & 2656 & 0.4 & 1.3 \\
\hline 1,6-Bis $(x$-methoxyphenyl)-3-heptene & 35 & 310 & 2731 & 0.8 & 0.6 \\
\hline 1,6-Bis ( $x$-methoxyphenyl)-hex-2(3 or 4)-en-1-one & 36 & 310 & 2773 & 0.3 & 0.1 \\
\hline $\begin{array}{l}\text { 2(3, } 4 \text { or } 5) \text {-Hydroxy-1,6-bis(x-methoxyphenyl)- } \\
\text { 1-hexanone }\end{array}$ & 37 & 328 & 2796 & 6.3 & 3.3 \\
\hline Isomer of $\mathbf{3 7}$ & 38 & 328 & 2825 & 2.4 & 1.3 \\
\hline
\end{tabular}




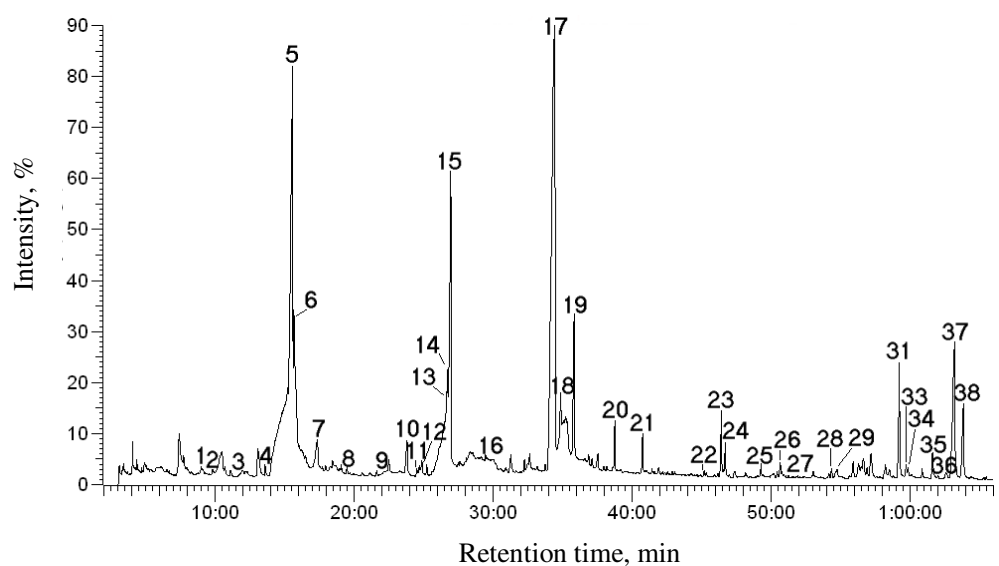

Figure 1. GC-MS chromatogram of aromatic compounds in manuka honey (A), Peak numbers refer to compounds numbered in Table 1

Pinocembrin (29) was the only flavonoid dectected in sample A. In addition to this compound, tectochrysin (30) and chrysin (32) were observed in sample B. In comparison with European honeys analysed using the same procedure ${ }^{14}$, the manuka honeys are significantly poor in flavonoids; both in variety and relative amount. Several compounds in Table 1 have never been reported to occur in honeys. They are; 2,3-dimethoxynaphthalene (14), 4-( $x$-methoxyphenyl)-1-phenyl-1-butanone (21), desoxyanisoin (23), 2,6-dimethoxybenzoic acid benzyl ester (24), 4,4'-dimethoxystilbene (25), 3,3,4,5,5,8-hexamethyl-2,3,5,6tetrahydro-s-indacene-1,7-dione (26) and 1,5-bis (4-methoxyphenyl)-pentane-1,5-dione (31). Their structures are given in Figure 2. Mass spectra of compounds 21 and 24 are not available in the literature and their structures were deduced from interpretation of their mass spectra as shown in Figure 3.

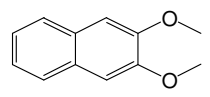

14

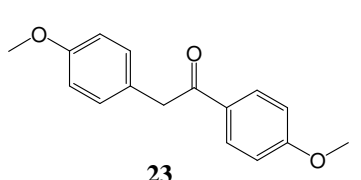

23

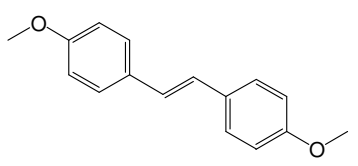

25

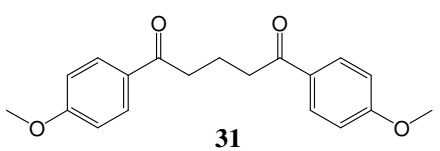<smiles>COc1ccc(CCCC(=O)c2ccccc2)cc1</smiles><smiles>COc1cccc(OC)c1C(=O)OCc1ccccc1</smiles><smiles>Cc1c2c(c(C)c3c1C(C)(C)CC3=O)C(C)(C)CC2=O</smiles>

26

Figure 2. Structures of aromatic compounds reported as honey constituents for the first time 

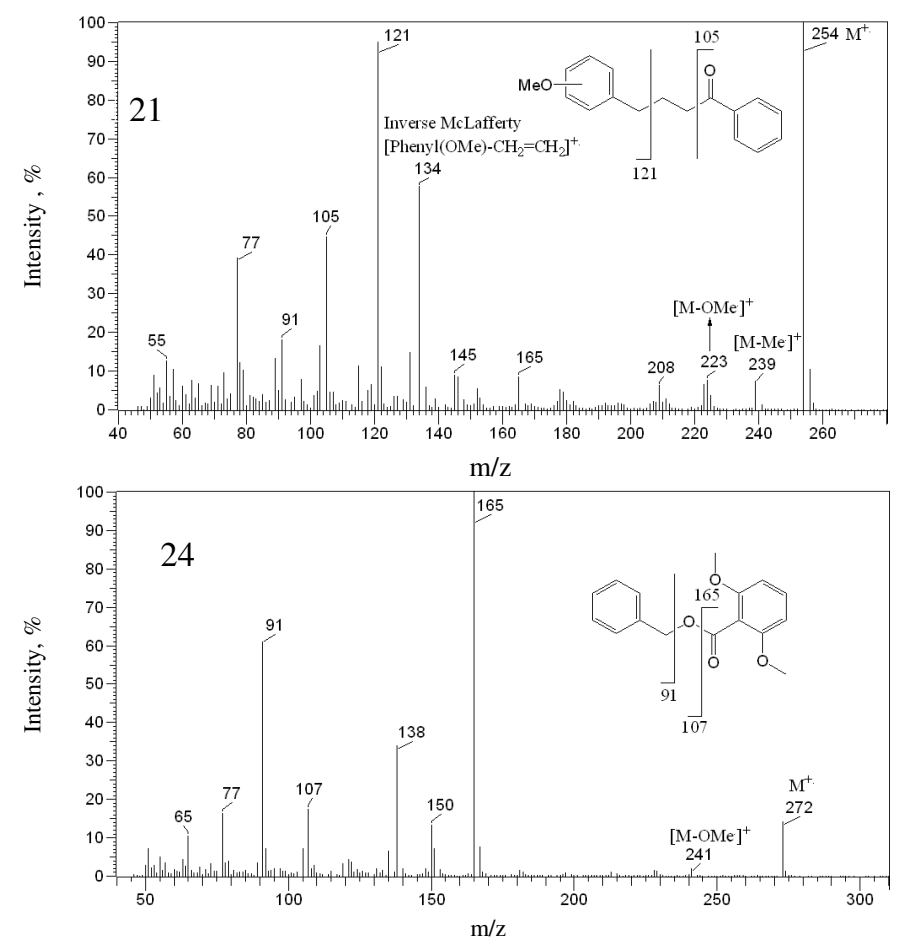

Figure 3. Spectra, structures and important fragments of 14-( $x$-methoxyphenyl)-1-phenyl-1butanone (21) and 2,6-dimethoxybenzoic acid benzyl ester (24)

Seven compounds, which are all 1, $n$-bis( $x$-methoxyphenyl)alkane derivatives are tentatively identified on the basis of their fragmentation patterns: 1,4-bis(xmethoxyphenyl)-but-2-en-1-one (28), 1,5-bis ( $x$-methoxyphenyl)- pent-3-en-1-one (33), 1,4-bis ( $x$-methoxyphenyl)-1-pentanone (34), 1,6-bis( $x$-methoxyphenyl)-3-heptene (35), 1,6-bis( $x$-methoxyphenyl)-hex-2(3 or 4)-en-1-one (36) and 2(3, 4 or 5)-hydroxy-1,6bis(x-methoxyphenyl)-1-hexanone (37 and 38). It is probable that the methoxysubstituents of these compounds are in the para-position but, in the absence of authentic standards this cannot be ascertained. These are all new compounds hitherto not reported in the chemical literature. Their mass spectra and formation of diagnostic fragments are shown in Figure 4(a-f).

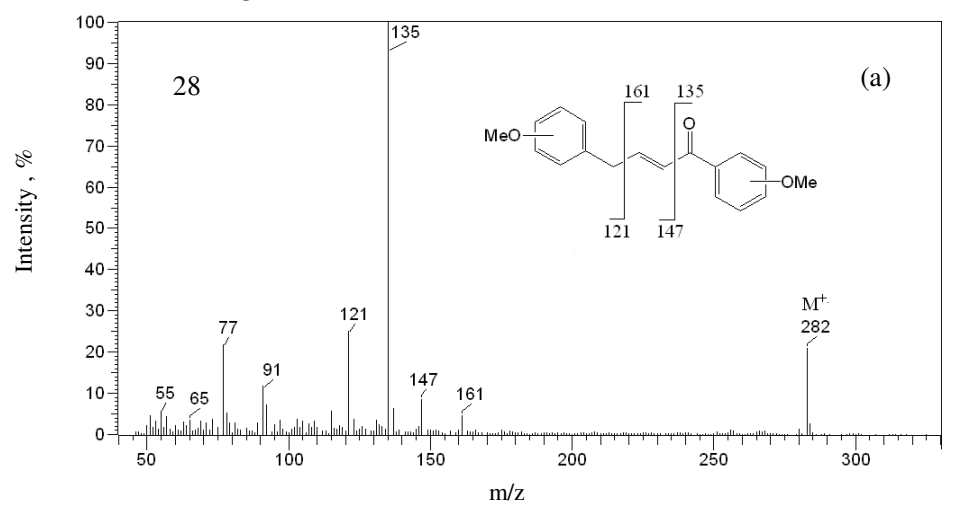



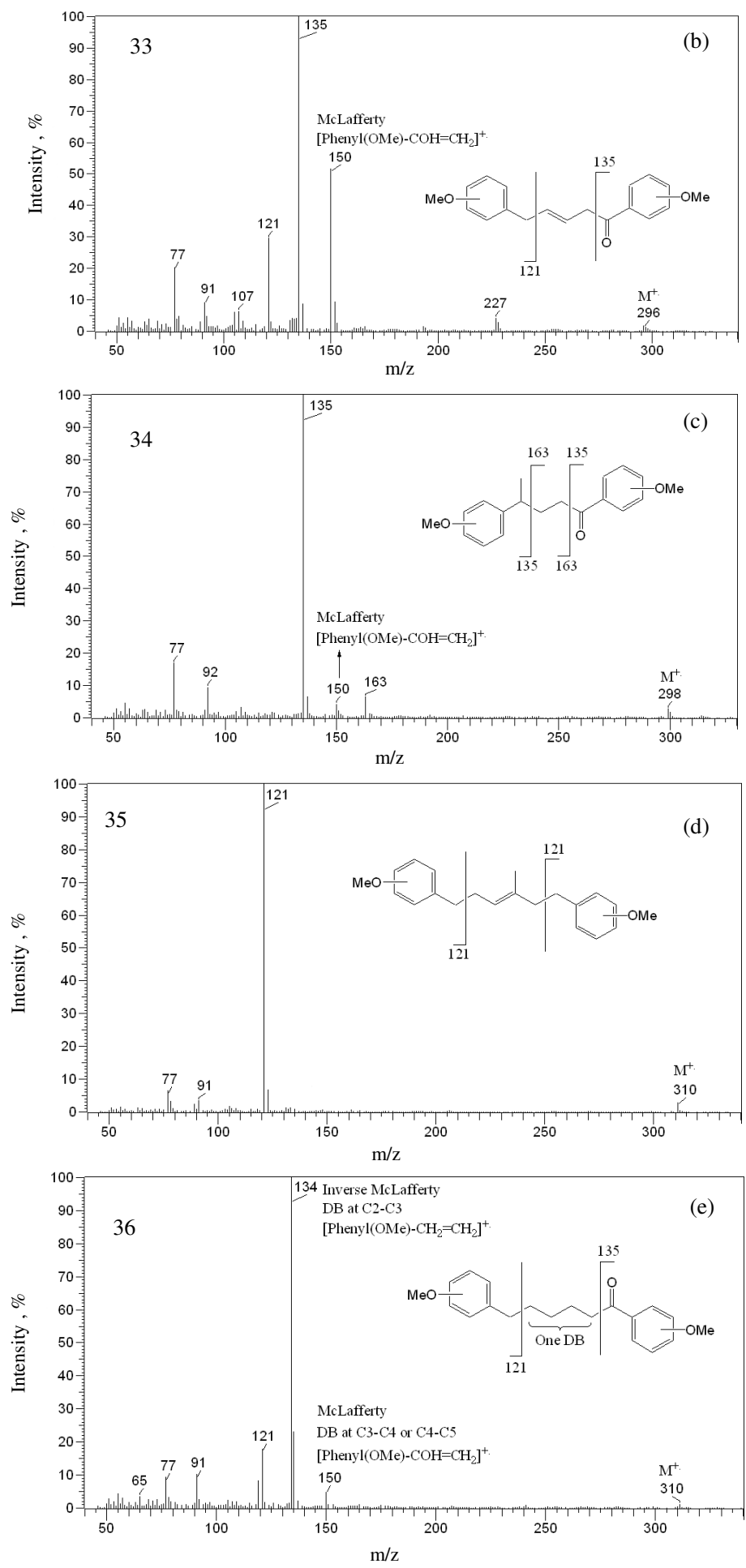


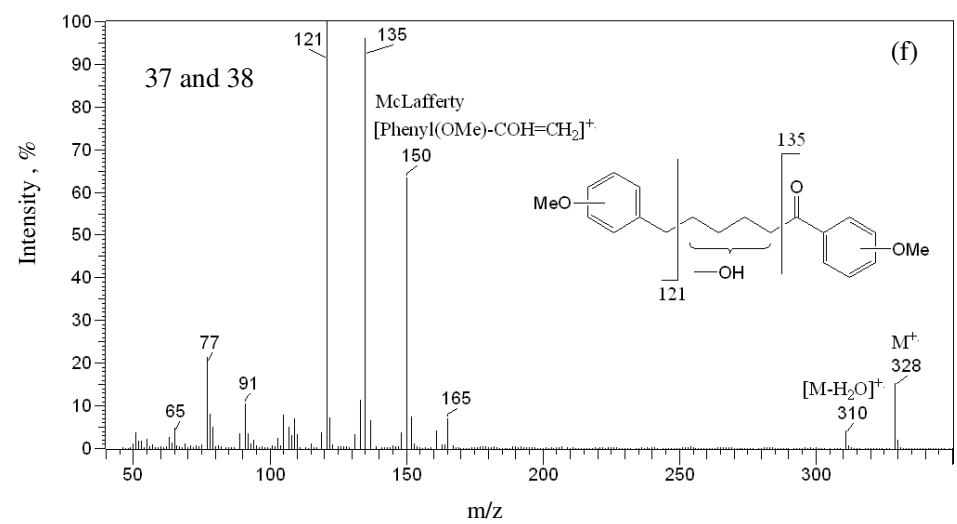

Figure 4. Spectra, structures and important fragments of new aromatic compounds (a) 28, (b) 33, (c) 34, (d) 35, (e) 36, (f) 37 and 38 found in manuka honey

Finally, three unidentified components 18, 19 and 20 were observed in both samples. The major fragments in the mass spectra of these compounds are listed in Table 2. Using liquid-liquid solvent extraction, Wilkins et al. ${ }^{17}$ found that phenyllactic acid and syringic acid were the most abundant organic compounds in manuka honey. Weston et al. ${ }^{4}$ showed moreover, that methyl syringate, which constituted $70 \%(\mathrm{w} / \mathrm{w})$ of the phenolic fraction, can be considered as a floral marker for this honey. In the present work, methyl syringate (17), ortho-methoxyacetophenone (5) and 3-phenyllactic acid (13) were found to be the major components of the SPME extracts: 32.3, 15.0 and $10.2 \%$ of total in sample $\mathbf{A}$ and 53.5, 7.0 and 6.5\% of total in sample $\mathbf{B}$, respectively.

Table 2. Mass spectral data of unknown compounds listed in Table 1

\begin{tabular}{cl}
\hline Compound No. & Mass $(\mathrm{m} / \mathrm{z})$ and Intensity $(\%$, in parentheses) of prominent MS peaks \\
\hline $\mathbf{1 8}$ & $77(20), 91(20), 131(65), 159(12), 202(100)$ \\
$\mathbf{1 9}$ & $55(26), 77(14), 91(12), 102(22), 115(22), 131(45), 158(13), 202(100)$ \\
$\mathbf{2 0}$ & $77(15), 115(12), 130(28), 158(35), 172(10), 184(6), 201(100)$ \\
\hline
\end{tabular}

Rivero-Cruz et al. ${ }^{18}$ showed the smooth muscle relaxant effect of benzylbenzoates, isolated from Brickellia veronicifolia, on guinea-pig ileum. Recently they demonstrated that among a series of spasmolytic benzylbenzoates, some compounds such as 2,4- and 3,4dimethoxybenzoic acid benzyl ester (isomers of 24) were the most active inhibitors of the system calmodulin-bovine brain ${ }^{19}$.

4,4'-Dimethoxystilbene (25) has been reported to be an agent that can decrease cellulite deposits $^{20}$. This property has been reported also for other substituted trans-stilbenes for their ability to inhibit the human tumor necrosis factor alpha-induced (TNF- $\alpha$ ) activation of transcription factor nuclear factor kappaB ${ }^{21}$.

\section{Conclusion}

The retailers of dietary products sell the manuka honey by claiming that it helps balance hormone levels. It normalizes menstruation and the symptoms of menopause. Isolation of the new compounds identified in this work and study of their biological activity (hormone balance) might provide new insight on the nutritional benefits of manuka honey.

\section{Acknowledgment}

This work was supported by the Swiss National Science Foundation (SNSF) (Grant No. 2140449.94). 


\section{References}

1. Russel K M, Molan P C, Wilkins A L and Holland P T, J Agric Food Chem., 1990, 38(1), 10-13.

2. Allen K L, Molan P C and Reid G M, J Pharm Pharmacol., 1991, 43(12), 817-822.

3. Somal N A, Coley K E, Molan P C and Hancock B M, J R Soc Med., 1994, 87(1), 9-12.

4. Weston R J, Brocklebank L K and Lu Y, Food Chem. 2000, 70(4), 427-435.

5. Cooper R A, Molan P C, Krishnamoorthy L and Harding K G, Eur J Clin Microbiol Infect Dis., 2001, 20(10), 758-759.

6. McGovern D P, Abbas S Z, Vivian G and Dalton H R, J R Soc Med., 1999, 92(8), 439.

7. Tonks A J, Dudley E, Porter N G, Parton J, Brazier J, Smith E L and Tonks A, J Leukocyte Biol., 2007, 82(5), 1147-1155.

8. $\quad$ Casey G and Van Rij A, N Z Med J., 1997, 110(1045), 216.

9. Molan P C and Russell K M, J Apic Res., 1988, 27, 62-67.

10. Weston R J, Mitchell K R and Allen K L, Food Chem., 1999, 64, $295-301$.

11. Weston R J, Food Chem., 2000, 71(2), 235-239.

12. Snow M J and Manley-Harris M, Food Chem. 2004, 84(1), 145-147.

13. Inoue K, Murayama S, Seshimo F, Takeba K, Yoshimura Y and Nakazawa H, J Sci Food Agric., 2005, 85, 872-878.

14. Daher S and Gülaçar F, J Agric Food Chem., 2008, 56, 5775-5780.

15. Schmalreck A F, Teuber M, Reininger W and Hartl A, Can J Microbiol., 1975, 21, 205-212.

16. Zhang W and Go M L, Eur J Med Chem., 2007, 42, 841-850.

17. Wilkins A L, Lu Y and Molan P C, J Apic Res., 1993, 32, 3-9.

18. Rivero-Cruz B, Rojas M A, Rodriguez-Sotres R, Cerda-Garcia-Rojas C M and Mata R, Planta Med., 2005, 71, 320-325.

19. Rivero-Cruz B, Rivero-Cruz I, Rodriguez-Sotres R and Mata R, Phytochem., 2007, 68(9), 1147-1155.

20. Okigami, Henry, Okigami and Paulo Takao (Brasil), Braz. Pedido PI, 2006, 13.

21. Heynekamp J J, Weber W M, Hunsaker L A, Gonzales A M, Orlando R A, Deck L M and Vander Jagt D L, J Med Chem., 2006, 49, 7182-7189. 


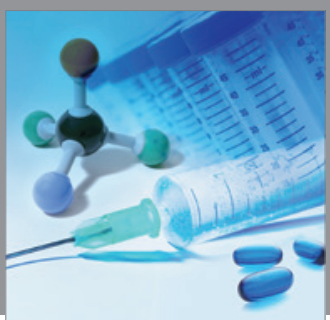

International Journal of

Medicinal Chemistry

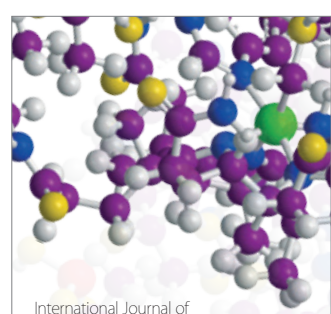

Carbohydrate Chemistry

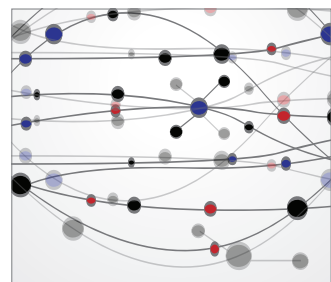

The Scientific World Journal
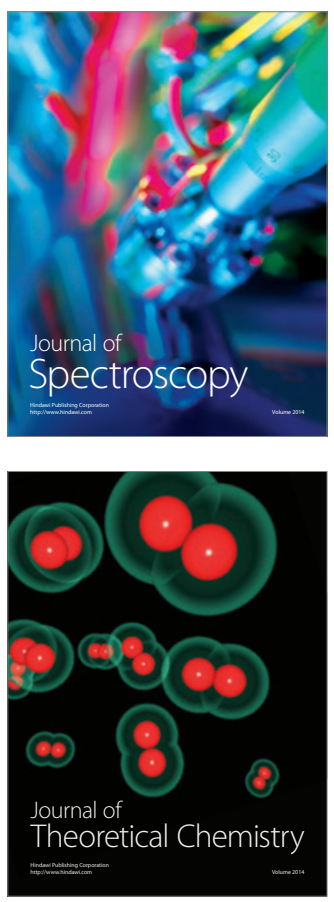
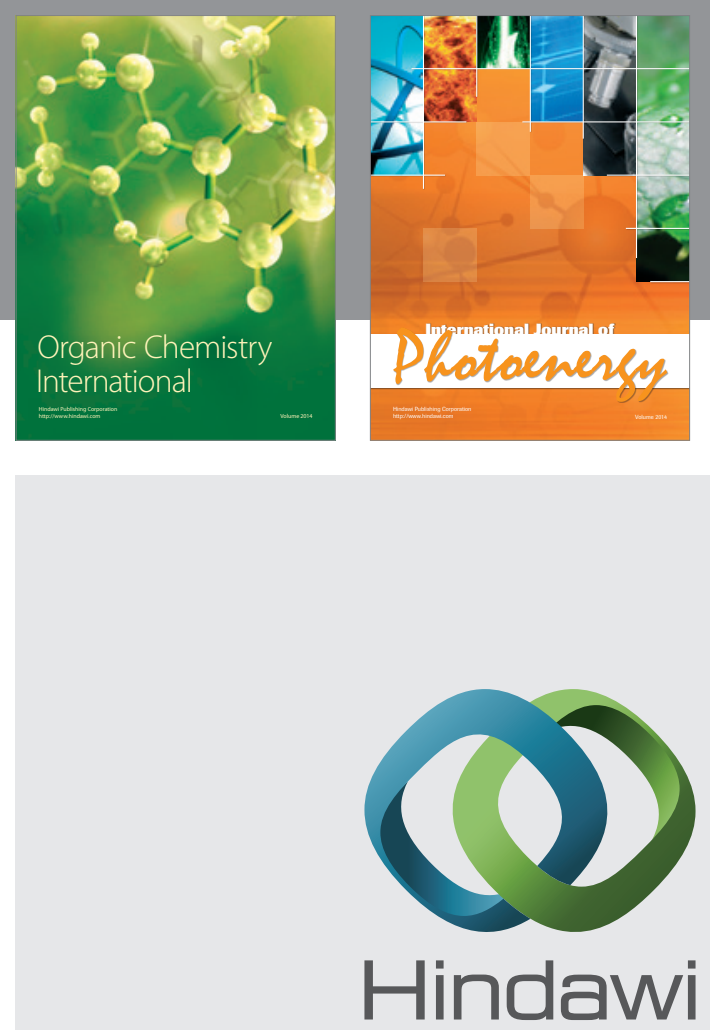

Submit your manuscripts at

http://www.hindawi.com
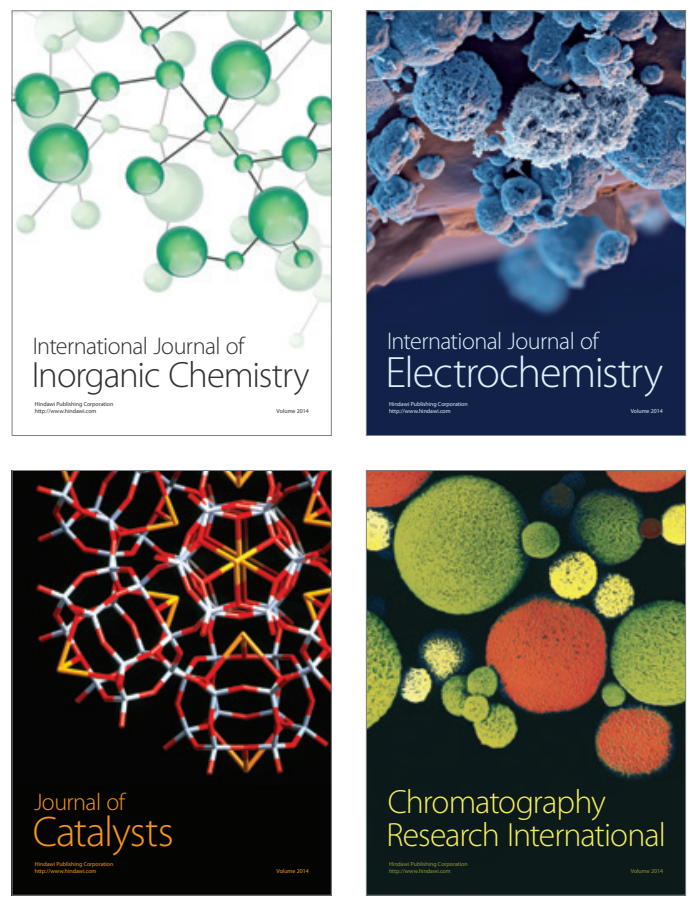
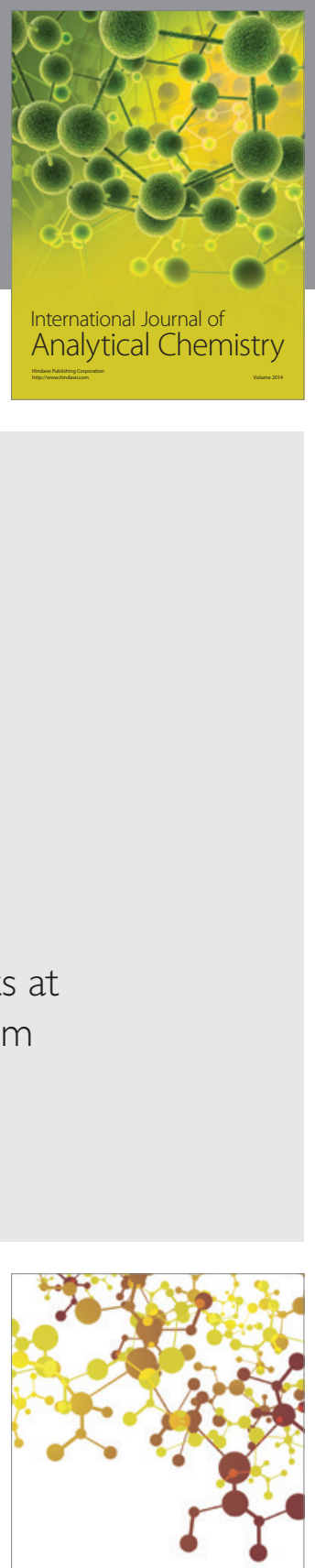

Journal of

Applied Chemistry
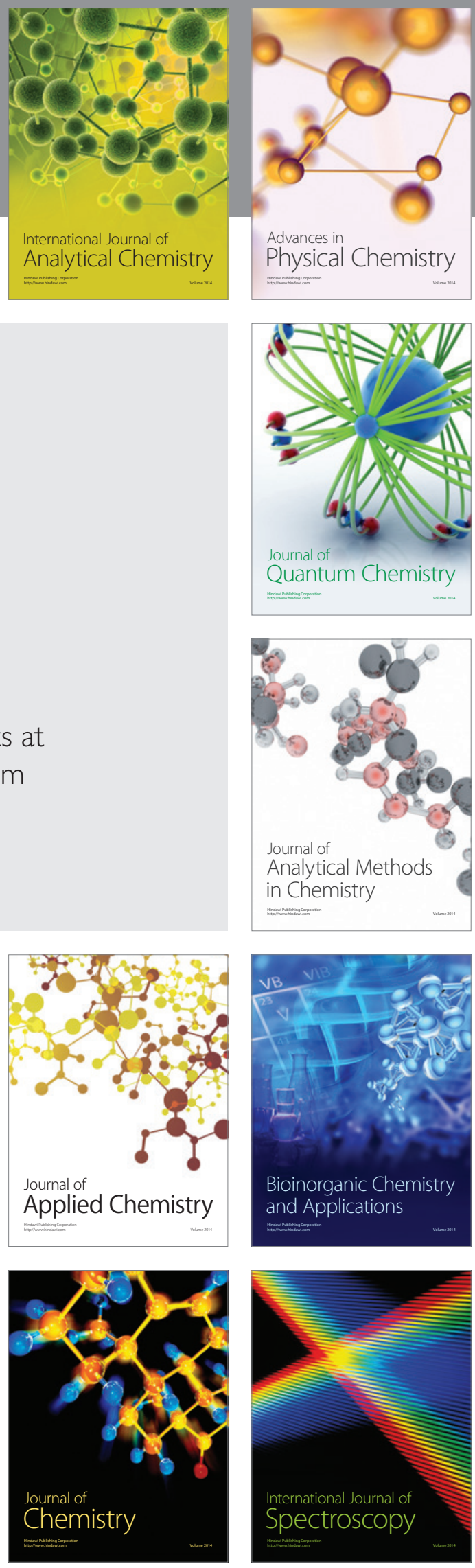